\title{
Contribuindo ao desenvolvimento sustentável: testes experimentais de um termossifão para aplicação em coletor solar de tubos a vácuo de alta pressão
}

Pedro Leineker Ochoski Machado pedmac@alunos.utfpr.edu.br Universidade Tecnológica Federal do Paraná (UTFPR), Ponta Grossa, Paraná, Brasil.

\section{Kaciane Aparecida Basílio} ka_basilio@hotmail.com

Universidade Tecnológica Federal do Universidade Tecnológica Federal do
Paraná (UTFPR), Ponta Grossa, Paraná, Brasil.

\section{Rogério de Oliveira Souza} rogerio98@outlook.com Universidade Tecnológica Federal do Paraná (UTFPR), Ponta Grossa, Paraná, Brasil.

Guilherme Antonio Bartmeyer gabartmeyer@hotmail.com Universidade Tecnológica Federal do Paraná (UTFPR), Ponta Grossa, Paraná Brasil.

\section{Thiago Antonini Alves} antonini@utfpr.edu.br

Universidade Tecnológica Federal do Paraná (UTFPR), Ponta Grossa, Paraná, Brasil.

\author{
RESUMO
}

Coletores solares são dispositivos que aquecem um fluido de trabalho por meio da irradiação solar. Um tipo de coletor solar de destaque é o de tubos à vácuo que utiliza termossifões como meio de transporte de energia térmica, permitindo que esses coletores apresentem elevada eficiência e sejam mais compactos. Neste trabalho foi realizado um estudo experimental do desempenho térmico de um termossifão comercial para aplicação em coletores solares de tubos à vácuo de alta pressão na inclinação de $25^{\circ}$ em relação à horizontal, referente à latitude da cidade de Ponta Grossa/PR: $25^{\circ} 05^{\prime} 42^{\prime \prime}$ Sul. O termossifão possui comprimento do evaporador de $1.700 \mathrm{~mm}$, diâmetro do evaporador e da seção adiabática de $8,2 \mathrm{~mm}$, comprimento da seção adiabática de $40 \mathrm{~mm}$, comprimento do condensador de $60 \mathrm{~mm}$ e diâmetro do condensador de $14,1 \mathrm{~mm}$. O condensador foi arrefecido por convecção forçada de água. $\mathrm{O}$ evaporador foi aquecido utilizando um resistor elétrico simulando a irradiação solar. 0 termossifão foi testado com o condensador acima do evaporador para cargas térmicas de $20 \mathrm{~W}$ a $60 \mathrm{~W}$. Os resultados experimentais mostraram que o termossifão comercial operou satisfatoriamente à inclinação de $25^{\circ}$ em relação à horizontal e está apto a operar em um coletor solar de tubos a vácuo de alta pressão nessas condições.
\end{abstract}

PALAVRAS-CHAVE: Coletores Solares. Termossifões. Energia Renovável. Desenvolvimento Sustentável. 


\section{INTRODUÇÃO}

O papel da energia na promoção do desenvolvimento econômico tornou-se, nas duas últimas décadas, alvo de pesquisas acadêmicas e políticas ambientais. Com isso, evidencia-se a busca de novas fontes e tecnologias renováveis que permitam a substituição de combustíveis não renováveis e de elevado potencial de degradação ambiental (KAREKEZLI \& KITHYOMA, 2003; LACERDA, 2015; ADAMS et al., 2018).

A busca da transição energética para fontes renováveis pode ser um dos principais desenvolvimentos recentes acerca do suprimento de energia sustentável. Isso porque além de se apresentarem como fontes relativamente limpas, as energias renováveis podem ser utilizadas de maneira descentralizada. Isso representa papel crucial na transição energética, uma vez que pessoas e indústrias passaram a investir em formas de energia para autoconsumo e que reduzem suas contas, levando a um setor de energia mais diversificado e com fornecimento democratizado, abrindo portas para novos entrantes nos mercados de energia (BRAUN et al., 2009; KAPHENGST \& VELTEN, 2014; HENTSCHEL et al., 2018).

Apesar dessa transição, a previsão para a produção de energia global no ano de 2020 consiste no uso majoritário de petróleo (30,18\% do total gerado), seguido por carvão $(28,11 \%)$, gás $(21,50 \%)$, bioenergia $(10,22 \%)$, energia nuclear $(5,50 \%)$, energia hidrelétrica $(2,52 \%)$, além de outras fontes renováveis $(1,97 \%)$. Percebe-se então que a maior parte da energia produzida provém de métodos degradantes ao meio ambiente (IEA, 2015).

Tratando-se do Brasil, ao se analisar dados fornecidos pelo Ministério de Minas e Energia (MME), o país é o que mais utiliza recursos renováveis em sua matriz energética. A Figura 1 apresenta a matriz energética brasileira referente à produção de energia no mês de julho/2019 (MINISTÉRIO DE MINAS E ENERGIA, 2019).

Figura 1 - Matriz de Produção de Energia Elétrica no Brasil: julho/2019

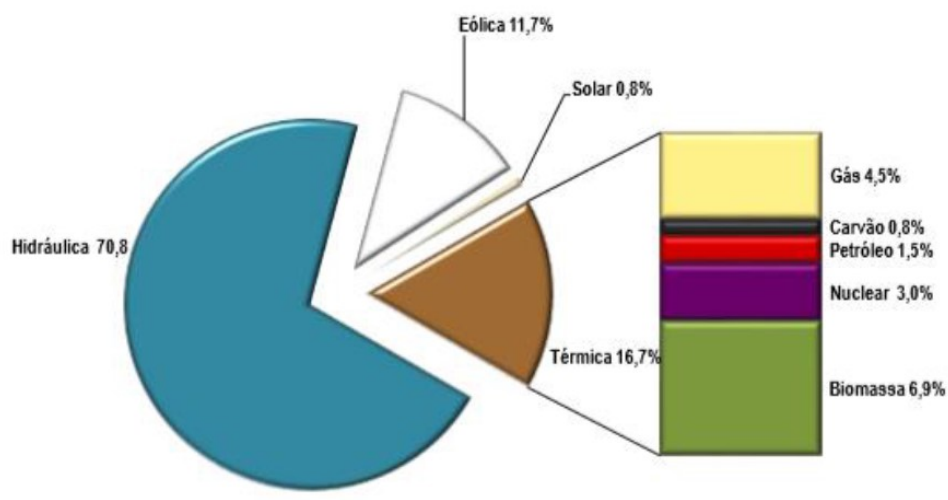

Fonte: Ministério de Minas e Energia (2019)

Conforme apresentado na Figura 1, a geração hidráulica representou 70,8\% da geração total do país, apresentando-se como o principal meio de produção de energia. Tratando-se de outras fontes renováveis, temos a geração eólica representando $11,7 \%$, a biomassa representando $6,9 \%$ e a geração solar $0,8 \%$. As 
fontes renováveis são responsáveis então por $90,2 \%$ da energia gerada no território brasileiro. Apesar de apresentar apenas $0,8 \%$, a geração solar foi um destaque nesse mês pelo fato de, em comparação com o mesmo mês do ano anterior, apresentar um crescimento de $90,4 \%$ na capacidade de geração instalada no território brasileiro (MINISTÉRIO DE MINAS E ENERGIA, 2019).

Mesmo com baixa geração em comparação com as demais fontes, o Brasil possui elevado potencial energético tratando-se da geração solar. Isso se deve ao fato de que a maior parte de seu território se encontra na região subtropical, já que a intensidade dos raios solares depende da latitude geográfica da área em questão e da estação do ano (PEREIRA et. al, 2017). A Figura 2 apresenta a média anual de irradiação solar no território brasileiro.

Figura 2 - Média anual de irradiação solar no território brasileiro

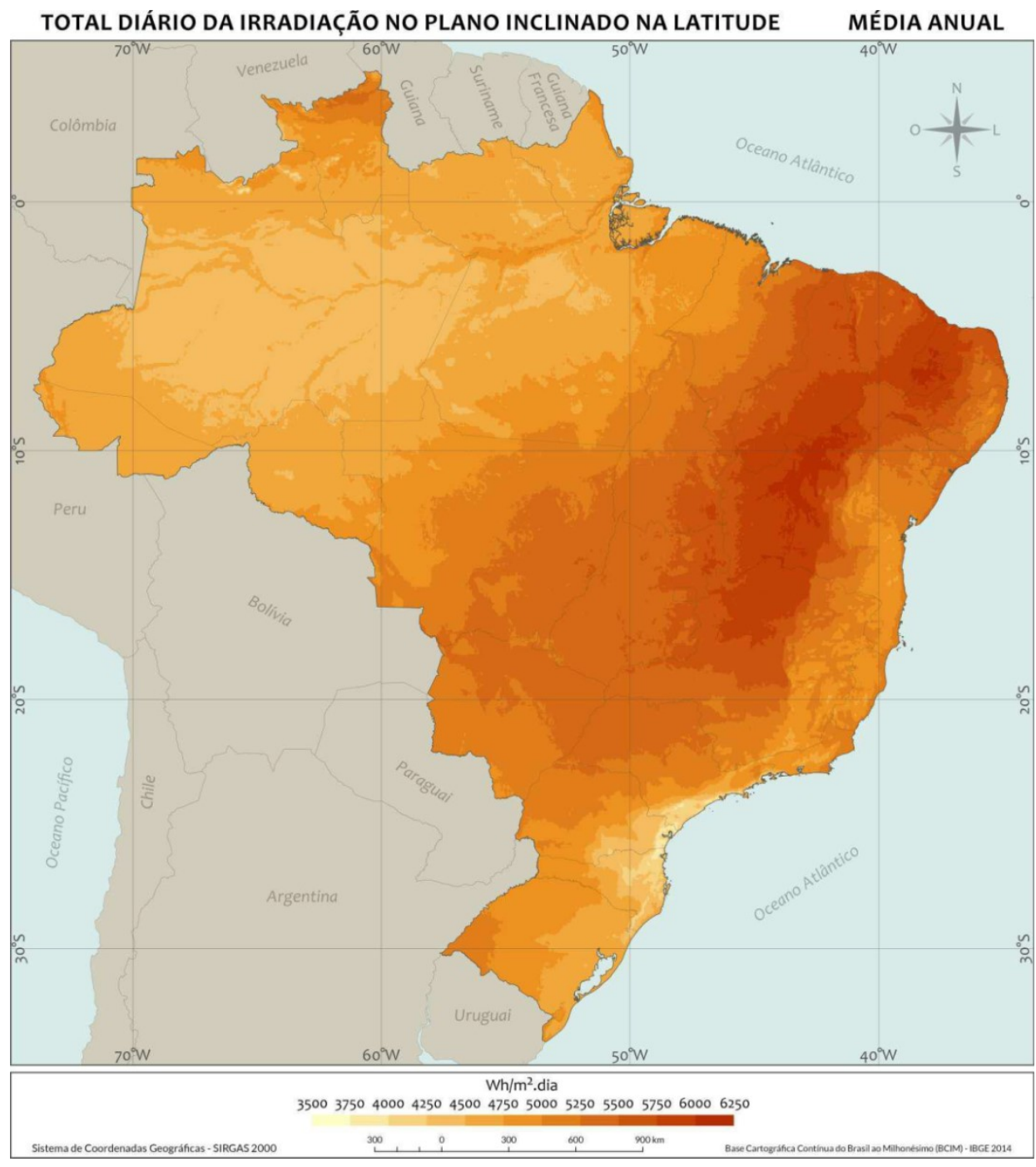

Fonte: Adaptado de Pereira et al (2017)

Uma das possíveis formas de se aproveitar tal potencial energético consiste no uso de dispositivos denominados coletores solares. Estes dispositivos recebem a irradiação solar e transferem energia para um fluido de trabalho (geralmente água) na forma de calor. Em termo de sua construção, essa deve ser baseada em 
especificações contidas nas normas ABNT NBR 15747:2008 (Sistemas Solares Térmicos e seus Componentes: Coletores Solares) e NBR 15569:2008 (Sistema de Aquecimento Solar de Água em Circuito Direto: Projeto e Instalação), em que se leva em conta dados como faixa de temperatura e pressão de operação, além da resistência de exposição à irradiação solar (MAIA JUNIOR et. al, 2016).

Um dos tipos de coletores solares disponível no mercado consiste no coletor solar de tubos à vácuo, pouco utilizado no Brasil, que utiliza termossifões para intensificar a transferência de calor para o fluido de trabalho que se deseja aquecer. Esse tipo de coletor, também denominado de coletor assistido por termossifões ou tubos de calor, é amplamente utilizado em países da Ásia, Estados Unidos, Canadá e Europa (MAIA JUNIOR et. al, 2016).

Tratando-se de termossifões, esses consistem em tubos de calor assistidos por gravidade, tendo como principal característica sua elevada eficiência devido ao fato de utilizaram calor latente de vaporização para transferir energia na forma de calor a altas taxas com pequenos gradientes de temperatura em distâncias consideráveis (REAY et al., 2014).

Os termossifões possuem como vantagem sua relativa simplicidade de construção, uma vez que são compostos por um tubo metálico evacuado e hermeticamente fechado contento fluido de trabalho em seu interior. Além disso, por utilizarem o calor latente de vaporização não utilizam potência de bombeamento externo para seu funcionamento, tornando-se uma alternativa viável para utilização em coletores solares, permitindo ainda que esses sejam mais compactos que os convencionais devido às altas taxas de transferência de calor (REAY et al., 2014).

A Figura 3 apresenta um diagrama esquemático do funcionamento de um termossifão.

Figura 3 - Diagrama esquemático de um termossifão

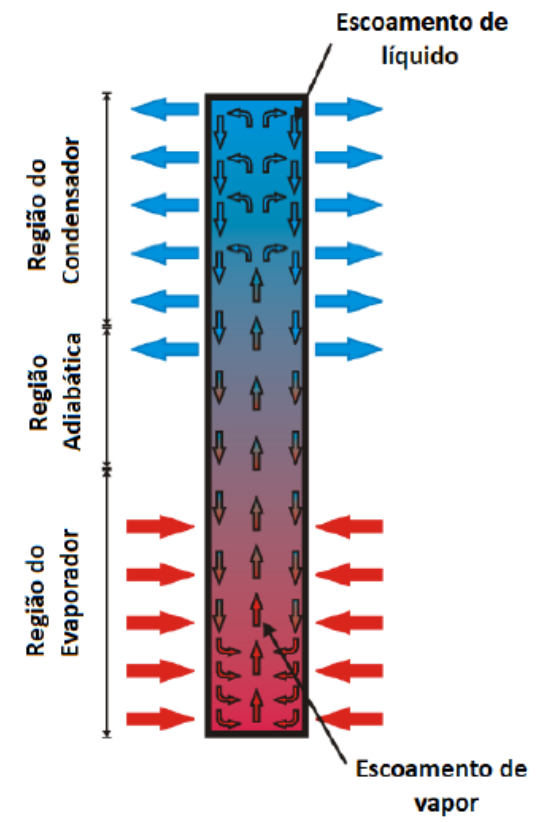

Fonte: Adaptado de Aguiar et al. (2018) 
Um termossifão pode possuir de duas a três regiões com diferentes funções em sua operação. Essas regiões recebem o nome de evaporador, seção adiabática (opcional) e condensador. $\mathrm{O}$ evaporador é a região que contém o fluido de trabalho no estado líquido, sendo então aquecido por uma fonte quente e ocasionando a evaporação desse fluido, que, devido à diferença de pressão, desloca-se para a região mais fria, denominada de condensador (região superior do tubo). No condensador o vapor gerado anteriormente dissipa energia como calor para uma fonte fria e é condensado, retornando ao evaporador como líquido, fechando o ciclo. A seção adiabática está localizada entre o evaporador e o condensador, não havendo transferência de calor entre o termossifão e o ambiente nessa região (MANTELLI, 2013).

Neste contexto, o presente trabalho apresenta uma análise experimental do desempenho térmico de um termossifão destinado ao uso em um coletor solar de tubos à vácuo de alta pressão e orientado a uma inclinação correspondente à latitude de Ponta Grossa/PR.

\section{CARACTERÍSTICAS DO TERMOSSIFÃO}

O termossifão analisado nesse estudo é de origem comercial, sendo um dos componentes do coletor solar de tubos à vácuo de alta pressão semelhante ao apresentado na Figura 4. Quando em funcionamento, tomando como base a Figura 5, a irradiação solar é absorvida pelo tubo à vácuo. Esse calor é dissipado então pelo condensador do termossifão para dutos de circulação em um mainfold em que se escoa água para aquecimento. Um anel centralizador e tubos concêntricos de borosilicato são utilizados para otimizar o funcionamento do sistema.

Figura 4 - Coletor solar de tubos à vácuo

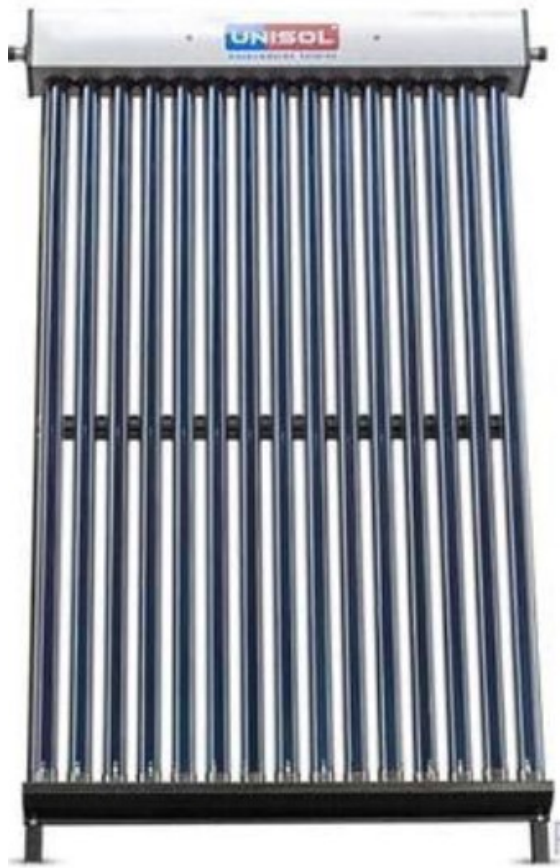

Fonte: PatroSol (2019) 
Figura 5 - Composição do coletor solar de tubos à vácuo de alta pressão

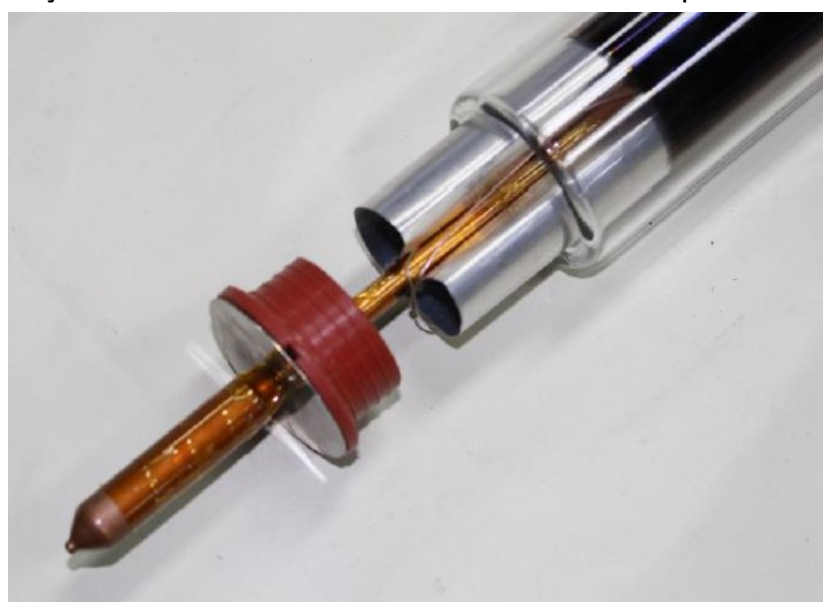

Tratando-se das dimensões, o termossifão de cobre analisado possui comprimento total de $1.800 \mathrm{~mm}$, com evaporador de comprimento de $1.700 \mathrm{~mm}$ e diâmetro externo de $8,2 \mathrm{~mm}$. A seção adiabática apresenta $40 \mathrm{~mm}$ de comprimento e diâmetro igual ao do evaporador. Enquanto o condensador apresenta comprimento de $60 \mathrm{~mm}$ e diâmetro externo de $14,1 \mathrm{~mm}$, ao passo que o fluido de trabalho, a razão de preenchimento (relação entre volume do fluido e volume do evaporador) e os diâmetros internos do termossifão são, até então, desconhecidos.

\section{METODOLOGIA EXPERIMENTAL}

Essa seção apresenta os procedimentos executados durante os testes experimentais.

\section{APARATO EXPERIMENTAL}

O aparato experimental utilizado neste estudo é apresentado na Figura 6 e foi composto por duas fontes de alimentação Politerm ${ }^{\mathrm{TM}} 16 \mathrm{E}$, um sistema de aquisição de dados Agilent ${ }^{\mathrm{TM}} 34970 \mathrm{~A}$ com multiplexador de 20 canais, um banho ultratermostatizado SOLAB $^{\mathrm{TM}}$ SL-130, um microcomputador portátil Dell ${ }^{\mathrm{TM}}$, um nobreak $\mathrm{NHS}^{\mathrm{TM}}$ e um rotâmetro de área variável Omega Engineering ${ }^{\mathrm{TM}}{ }^{\mathrm{FL}-2051}$ com válvula reguladora.

\section{PROCEDIMENTO EXPERIMENTAL}

O termossifão foi fixado na bancada por meio de garras e mantido a uma inclinação de $25^{\circ} \mathrm{com}$ a horizontal, correspondendo a latitude da cidade de Ponta Grossa/PR: $25^{\circ} 05^{\prime} 42^{\prime \prime}$ Sul. O teste consistiu em aplicar diferentes valores de cargas térmicas na região do evaporador do termossifão enquanto a região do condensador foi arrefecida à água. 
Figura 6 - Aparato Experimental

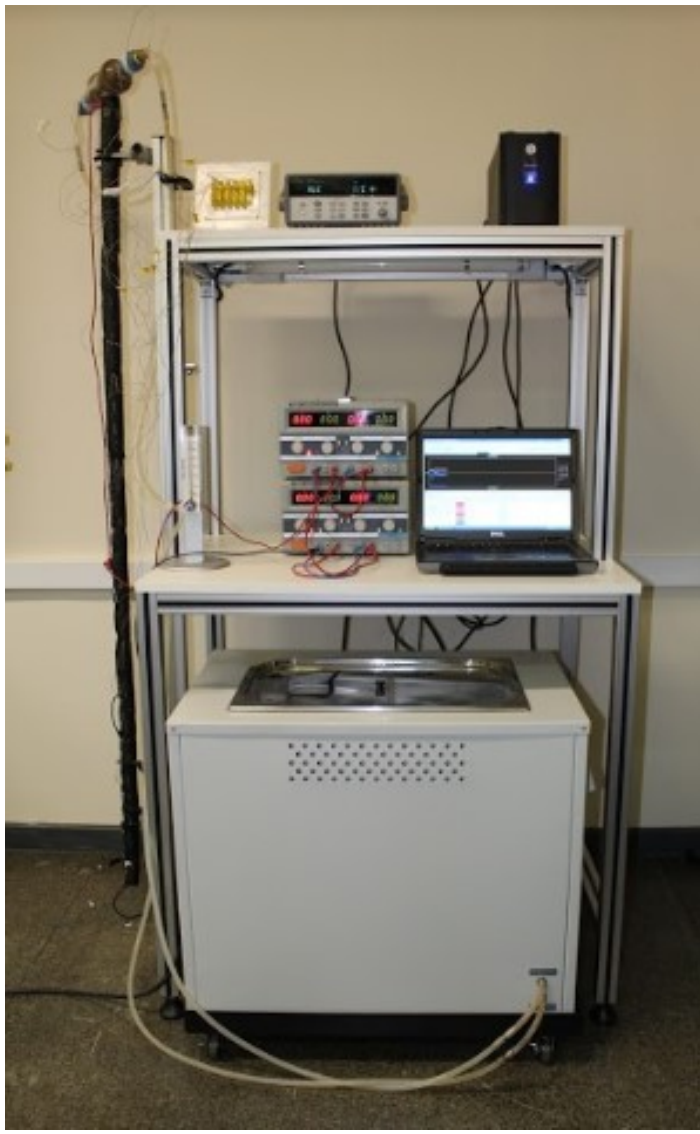

As cargas térmicas foram obtidas por meio do efeito Joule pela dissipação controlada de potência oriunda de fontes de potência em uma fita resistiva. Esta dissipação de energia térmica simula a irradiação solar. Os ensaios foram realizados alterando as cargas térmicas de $20 \mathrm{~W}$ até $60 \mathrm{~W}$, variando a potência com um passo de $20 \mathrm{~W}$. $\mathrm{O}$ arrefecimento foi realizado por um escoamento de água fornecido pelo banho ultratermostatizado a uma temperatura de $16,0{ }^{\circ} \mathrm{C} \pm$ $0,5^{\circ} \mathrm{C}$ e vazão volumétrica de $1,0 \mathrm{~L} / \mathrm{min}$, medido pelo rotâmetro de área variável e transportado por mangueiras de silicone (Figura 6). A temperatura ambiente foi mantida por um sistema de ar condicionado Rhemm ${ }^{\mathrm{TM}}$ em $16,0^{\circ} \mathrm{C} \pm 0,5^{\circ} \mathrm{C}$, buscando igualar a temperatura do banho ultratermostatizado.

A região do evaporador do termossifão foi protegido por fita termossensível Kapton $^{\mathrm{TM}}$, tendo uma fita resistiva de liga de níquel-cromo Omega Engineering ${ }^{\mathrm{TM}}$ enrolada em toda a região. O evaporador e a região foram protegidos com isolamento térmico aeronáutico e uma camada de poliuretano para evitar troca térmica com o ambiente. Os dados de temperatura foram obtidos utilizando termopares do tipo $\mathrm{K}$ Omega Engineering ${ }^{\mathrm{TM}}$ fixados por fitas termossensível Kapton ${ }^{\mathrm{TM}}$ e isolante $3 \mathrm{M}^{\mathrm{TM}}$. Ao todo foram utilizados 7 termopares na região do evaporador, um na seção adiabática e um no condensador, além de dois termopares para medir a temperatura de entrada e saída da água. 


\section{RESULTADOS E DISCUSSÃO}

A Figura 7 apresenta a distribuição de temperaturas do termossifão em função do tempo e da potência dissipada. Os termopares do evaporador estão apresentados de $T_{\text {evap }, 1}$ até $T_{\text {evap,7, a seção adiabática e do condensador são }}$ representados por $T_{\text {adiab }}$ e $T_{\text {cond, }}$, respectivamente, enquanto que as temperaturas de entrada e saída da água são representadas por $T_{\text {ent }}$ e $T_{\text {sai }}$.

Figura 7 - Distribuição de temperaturas do termossifão em função do tempo e da potência dissipada

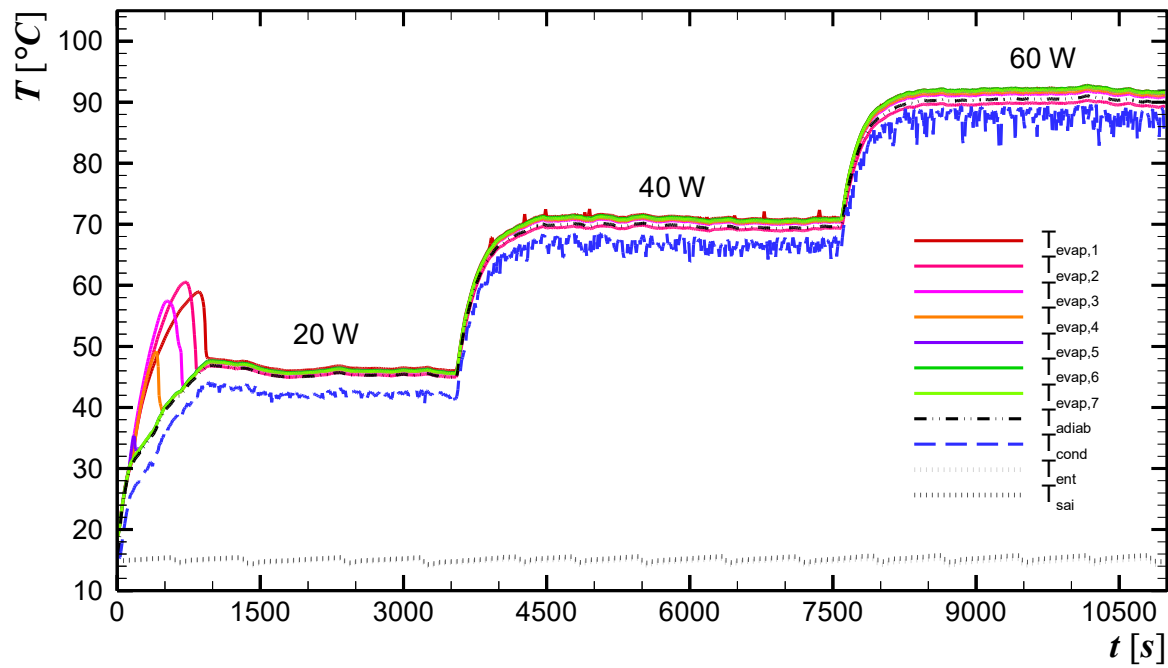

Como pode ser observado na Figura 7, o termossifão se comportou conforme o esperado. Nos primeiros instantes em que se aplica os valores de potência na fita resistiva ocorre um aumento nas temperaturas lidas pelos termopares, até o momento em que todo o sistema atinge o regime quasi permanente, mantendo os valores de temperatura aproximadamente constantes até que se varie a potência dissipada novamente.

Além disso, percebe-se que a temperatura do condensador sempre se manteve abaixo das temperaturas do evaporador, condizendo com o princípio de funcionamento de um termossifão. Uma das possíveis causas para a variação dos valores de temperatura no condensador seria o fato da variação da temperatura da água fornecida pelo banho, uma vez que, como percebido pelos valores de $T_{\text {ent }}$, não foi mantida constante pelo fato de o banho ligar e desligar seu controle de temperatura de acordo com a necessidade.

Em relação aos valores de temperatura obtidos ao se dissipar $20 \mathrm{~W}$ pode-se perceber que as temperaturas chegaram próximas de $60^{\circ} \mathrm{C}$ até entrarem em regime quasi permanente perto dos $45^{\circ} \mathrm{C}$. Isso se deve ao tempo necessário para que se estabilize o funcionamento do termossifão, uma vez que a temperatura do fluido de trabalho tende a reduzir no momento em que se começa a ter o retorno do fluido condensado vindo do condensador.

Em relação às temperaturas de entrada e saída da água, percebe-se que quanto maior a potência dissipada maior a diferença entre essas temperaturas. Tal diferença acaba sendo pequena pelo fato de que após passar pelo termossifão a água retorna ao banho aonde é novamente resfriada para a temperatura de entrada, o que não aconteceria realmente em um coletor solar, 
onde a água circularia pelo coletor por várias vezes até atingir a temperatura desejada.

A Figura 8 apresenta os dados de temperatura de operação do termossifão em função da potência dissipada. Tomou-se como referência a temperatura da seção adiabática como temperatura de operação.

Figura 8 - Temperatura de operação em função da potência dissipada

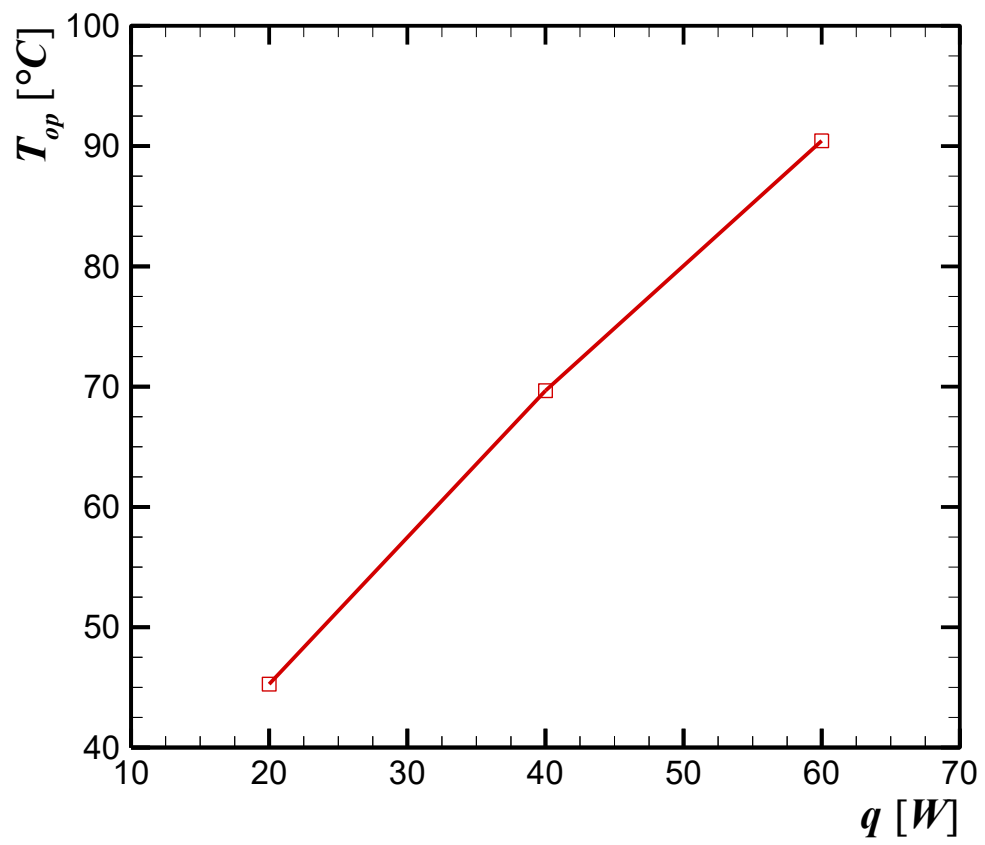

Como esperado, a temperatura de operação aumentou conforme se aumenta a potência dissipada, operando a cerca de $45^{\circ} \mathrm{C}$ a $20 \mathrm{~W}$ e próximo de $90^{\circ} \mathrm{C}$ a $60 \mathrm{~W}$, tendo como significado físico a temperatura de operação representando a temperatura do vapor no interior do termossifão.

A Figura 9 apresenta dados referentes à resistência térmica $\left(R_{t}\right)$ do termossifão em função da potência dissipada. A resistência térmica foi determinada pela Equação (1), em que $T_{\text {evap }}$ consiste na média entre $T_{\text {evap }, 1}$ a $T_{\text {evap, }}$ no momento em que se atinge o regime quase permanente e $q$ corresponde à potência dissipada

$$
R_{t}=\frac{T_{\text {evap }}-T_{\text {cond }}}{q}
$$

$\mathrm{Na}$ Equação (1), quanto maior a potência dissipada, menor tende a ser o valor da resistência térmica, uma vez que $R_{t}$ é inversamente proporcional ao valor de $q$ e a diferença entre temperaturas do evaporador e condensador manteve-se muito próxima ao longo das potências dissipadas. De forma geral, percebe-se que o termossifão operou satisfatoriamente na inclinação referente à latitude de Ponta Grossa/PR, mostrando-se apto ao uso em coletor solar de tubos à vácuo de alta pressão nessa inclinação, já que conseguiu operar como esperado até uma carga térmica de $60 \mathrm{~W}$. 
Figura 9 - Resistência Térmica em Função da Potência Dissipada

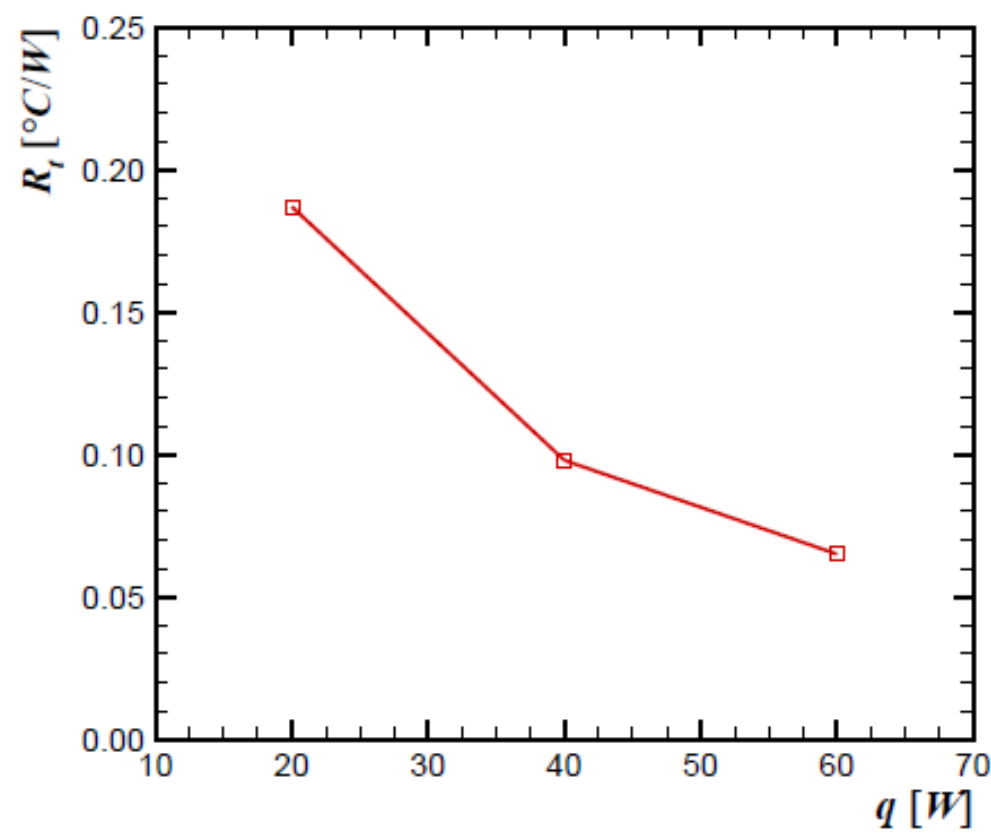

\section{CONCLUSÃO}

Neste trabalho foi realizada uma avaliação experimental do desempenho térmico de um termossifão comercial para coletores solares à vácuo operando em uma inclinação de $25^{\circ}$ em relação à horizontal. O termossifão operou de forma satisfatória com uma carga térmica de até $60 \mathrm{~W}$, mostrando-se apto para operar em tais condições em um coletor solar de tubos à vácuo de alta pressão.

\section{AGRADECIMENTOS}

Agradecimentos são prestados à CAPES, à Pró-Reitoria de Pesquisa e PósGraduação da UTFPR, à Diretoria de Pesquisa e Pós-Graduação, ao Programa de Pós-Graduação em Engenharia Mecânica e ao Departamento Acadêmico de Mecânica da UTFPR/Câmpus Ponta Grossa. 


\title{
Contributing to sustainable development: experimental testing of a thermosyphon for high pressure vacuum tube solar collector application
}

\begin{abstract}
Solar collectors are devices that heat a working fluid through solar irradiation. A prominent type of solar collector is the vacuum tubes type that use thermosyphons as a means of transporting thermal energy, allowing these collectors to be highly efficient and more compact. In this work we performed an experimental study of the thermal performance of a commercial thermosyphon for application in high pressure vacuum tube solar collectors at an angle of $25^{\circ}$ to the horizontal, referring to the latitude of the city of Ponta Grossa/PR: $25^{\circ} 05^{\prime} 42$ "South. The thermosyphon has an evaporator length of 1,700 $\mathrm{mm}$, an evaporator and adiabatic section diameter of $8.2 \mathrm{~mm}$, an adiabatic section length of $40 \mathrm{~mm}$, a condenser length of $60 \mathrm{~mm}$, and a condenser diameter of $14.1 \mathrm{~mm}$. The condenser was cooled by water forced convection. The evaporator was heated using an electric resistor simulating the solar irradiation. The thermosyphon was tested with the condenser above the evaporator for thermal loads from 20 to $60 \mathrm{~W}$. Experimental results show that the commercial thermosyphon operates satisfactorily at the inclination of $25^{\circ}$ from the horizontal and it is able to operate on a vacuum tube solar collector under these conditions.

KEYWORDS: Solar Collectors. Thermosyphons. Renewable Energy. Sustainable Development.
\end{abstract}


ADAMS, S.; KLOBODU, E. K. M.; APIO, A. Renewable and non-renewable energy, regime type and economic growth. Renewable Energy, v. 125, p. 755-767, 2018. crossref

AGUIAR, V. M. et al. Thermal analysis of a finned thermosyphon for heat exchanger applications. International Journal of Advanced Engineering Research and Science, v. 5, n. 1, 2018. crossref

BRASIL. Ministério de Minas e Energia. Boletim Mensal de Monitoramento do Sistema Elétrico Brasileiro Julho/2019. Brasília/DF: MME, 2019.

BRAUN, Martin et al. Photovoltaic self-consumption in Germany: using lithiumion storage to increase self-consumed photovoltaic energy. In: 24th European Photovoltaic Solar Energy Conference (PVSEC), Hamburg, Germany. 2009.

HENTSCHEL, M.; KETTER, W.; COLLINS, J. Renewable energy cooperatives: Facilitating the energy transition at the Port of Rotterdam. Energy Policy, v. 121, July 2017 , p. 61-69, 2018. crossref

IEA, 2015. World Energy Outlook 2015, International Energy Agency, Paris.

KAPHENGST, T.; VELTEN, E. K. Energy transition and behavioural change in rural areas-The role of energy cooperatives. WWWforEurope Working Paper, 2014.

KAREKEZI, S. KITHYOMA, W. Renewable and Rural Energy Development. The Workshop for African Energy Experts on Operationalizing the NEPAD Energy Initiative Operationalizing the NEPAD Energy Initiative, 2003. Novotel, Dakar, Senegal, 2-4 June, 2003.

LACERDA, K. A. Remodelagem de uma usina sucroalcooleira para incremento da cogeração de energia com aproveitamento do palhiço. Ilha Solteira, 161 p., 2015. Dissertação (Mestrado em Engenharia Mecânica) - Universidade Estadual Paulista "Júlio de Mesquita Filho".

MAIA JUNIOR, G. N. et. al. Contribuindo ao desenvolvimento sustentável: proposta de um coletor solar compacto assistido por termossifões. In: CONGRESSO BRASILEIRO DE ENGENHARIA DE PRODUÇÃO, 6., Ponta Grossa/PR. Anais... Ponta Grossa/PR: UTFPR/Câmpus Ponta Grossa, 2016. 
MANTELLI, M.B.H. Thermosyphon Technology for Industrial Applications. Chapter 11, In: Vasiliev L.L. and Kakaç S. (Eds.), Heat pipes and solid sorption

transformations: fundamentals and practical applications. CRC Press, Boca Raton, USA, 54 p., 2013. crossref

PATROSOL, 2019. Coletor Aquecedor Solar Modular a Vácuo 30 Tubos UNISOL. Disponível online em < https://www.patrosol.com.br/vacuo/coletor-aquecedorsolar-modular-a-vacuo-30-tubos>. Acesso em 15 de out. de 2019.

PEREIRA, E. B. et al. Atlas Brasileiro de Energia Solar. 2. ed. São José dos Campos, 2017.

REAY, D. A.; KEW, P. A.; MCGLEN, RJ. Heat Pipe: Theory, Design and Applications, Butterworth-Heinemann, Amsterdam, NED, 2014.

MACHADO, P. L.O. et al. Contribuindo ao desenvolvimento sustentável: testes experimentais de um termossifão para aplicação em coletor solar de tubos a vácuo de alta pressão. R. Gest. Industr., Ponta Grossa, v. 15, n. 4, p. 01-13, Out./Dez. 2019. Disponível em: http://periodicos.utfpr.edu.br/revistagi. Acesso em: 2019.

Correspondência:

Pedro Leineker Ochoski Machado

Universidade Tecnológica Federal do Paraná, Ponta Grossa, Paraná, Brasil.

Direito autoral: Este artigo está licenciado sob os termos da Licença Creative Commons-Atribuição 4.0 Internacional.

(c) (1) 